\title{
The Impact on Distribution Network of Distributed Power
}

\author{
Liruo Lu ${ }^{a}$, Mengqing Jia ${ }^{b}$, Yanli Chang, Yanping Chen \\ State Grid Henan Electric Power Company Luoyang Power Supply Company, \\ Luoyang 471000, China \\ a3481042@qq.com, b284307335@qq.com
}

Keywords: Distribution network, Distributed power, Power supply.

\begin{abstract}
As more and more distributed power access to distribution network system, distribution network planning based distributed generation technology will become a hot research. Depending on the relevant starting point for planning a distributed power supply can be divided into two cases: distributed power distribution in the power network planning and consideration of distributed power distribution network expansion plans, the former power plan as a starting point, and the latter to grid planning as a starting point. In this paper, the impacts of these two cases were studied grid.
\end{abstract}

\section{Introduction}

Distributed generation refers to meet the specific needs of users, to support the economic operation of existing distribution networks or satisfy these two requirements, and the user in the user's site or near-site configuration of several kW to $50 \mathrm{MW}$ of power for small, and the Environment compatible generators. From a broader definition, distributed generation refers to any generating facilities installed in the vicinity of the user, including CHP, CCHP and a variety of energy storage technologies, regardless of the size of this generation form and the type of primary energy use.

With more and more distributed power access to distribution network, grid planners must consider the impact of distributed power. When a large number of distributed powers had been in the plan, there are a lot of random variations, so that the complexity of the power system is greatly increased. There is not enough capacity, the traditional planning methods to solve programming including distributed power, mainly because of the traditional planning methods in varying degrees simplifies programming questions about planning the expression of uncertainty is difficult to quantify objectively exist, lack of a better way. Emergence of distributed generation to the traditional distribution network planning has brought significant challenges when selecting the optimal solution, the impact must be considered by it brings, making distribution network planning studies, focus on improving grid planning.

\section{The Distribution Planning of Distributed Power}

Distributed grid operation allows power system load forecasting, planning and operations to greater uncertainty than ever before, but in adding distributed power can reduce the power consumption, can delay or reduce the investment to upgrade the grid, but if the location and size of the distributed power inappropriate, but may lead to increased energy consumption, resulting in a voltage drop of some nodes in the network, or over-voltage, fault current will change the size, duration and direction. See on the site and the volume of distributed power is a huge multi-objective optimization problem, as well as between the various sub-optimization goals may be mutually contradictory constraints, distributed power distribution network for solving the problem must be able to accurately plan distributed power assessment, in which the grid, the best location and size of the distributed power given to make the process of the gradual penetration of distributed power grid without damage to affect the safety and economy of the grid.

The traditional distribution network planning consideration period is generally 5 to 20 years, in this age, is usually assumed power load growth year after year, the new MV / LV node continue to 
emerge, the result will be one or more additional substation, due to dynamic properties of programming problems associated with its dimension (usually taking thousands of nodes), if more nodes there were many generators, will make all possible to find the optimal network structure of the network layout scheme ( you can make the construction costs, maintenance costs and minimal power loss program) even more difficult.

For those who want to install DG in distribution network users or independent power company, they want to maintain and there are some conflicts between the existing security systems and power quality levels of the same distribution network companies. This is because a large number of DG access distribution system operation, the structure of the distribution system will have a profound impact, making the distribution network dependence on large power plants and transmission gradually reduced the original one-way power flow characteristics also occurred feed changes, a series of comprehensive distribution network problems caused by the distributed generation technologies including operating voltage regulation and reactive power balance and protection, etc. complicate the affected system.

When a large number of distributed power appears in the plan, a large number of random variation makes the complexity of the power system is greatly increased. The traditional planning methods without adequate ability to solve programming problems containing distributed power, mainly because the traditional planning methods have varying degrees of planning issues will be simplified, for the uncertainty is difficult to quantify the expression of a lack of planning in the objective existence of a better approach.

\section{The Impact on Trend of Distributed Power}

Traditional power flow is flowing from the substation each load, but when distributed generation access, the trend is no longer a one-way flow from the power user side, the trend of change in the way in low voltage distribution network will have an important impact.

DG makes a lot of access to a large distribution network relies on the gradual reduction of power plants and transmission, the original properties of unidirectional power feeding the trend has also undergone great changes. Therefore, a reasonable choice of the location and capacity of distributed power supply is very important domestic and foreign scholars have been distributed power sitting and sizing do the research. DG best position to determine the pressure levels in the distribution network can be considered feeder capacity limits, feeder voltage three-phase short-circuit current forms and other technical constraints, and establish a network expansion and net loss of least-cost objective function, genetic algorithm DG is installed on the location and capacity of the size optimization. Radial chain distribution network in some capacity incorporated after each load distributed power node voltage magnitude there are some changes, some domestic scholars have conducted research, the model is extended to general continuous analytical form of voltage distribution Features and feasible access location and the injection of distributed generation capacity limits were discussed theoretically. Studies have shown that, from the perspective of the steady-state voltage, distributed power access locations and specific injection feeder size capacity due to more stringent theoretical analysis based on the job.

Three kinds of common interface with the grid interconnection of DG forms: synchronous generators, induction generator and DC / AC or AC / AC converter. For the distribution network of different types of distributed power and voltage regulation device that can establish the corresponding steady-state model: Synchronous Motor access to distributed power grid nodes with PV simulation; with asynchronous generators access to distributed power grid PQ node is used to simulate; power converter interface flow calculation requires the use of control strategies converter for analysis. Since many distributed generation caused by load changes and forecast uncertainty makes the network flow distribution is uncertain, the larger impact of wind power and photovoltaic power generation systems, climate and other natural conditions, randomness obvious 


\section{The Impact on Power Quality of Distributed Power}

DG access after distribution network, a large number of power electronic converters increases the nonlinear load will cause harmonic pollution, the impact of DG on power quality is mainly reflected in two aspects:

(1) The voltage flicker. The main reason causing voltage flicker DG are: to start a large-scale distributed units, distributed sudden changes in output, distributed unit and the feedback link voltage feedback control affect device interaction. Solutions currently used require the owner to reduce the number of starts distributed units distributed unit.

(2) It is easy to produce a large number of harmonics. Since the DG itself is a harmonic source, and DG is based on power electronics technology through an inverter access to the distribution network, thus inevitably bring a lot of harmonics.

Although the introduction of DG will cause a large number of harmonics and voltage flicker, but on the other hand, DG there is the potential to improve power quality, when associated with the network load is large, DG can be quickly put to use to make the system as much as possible to reduce the failure, thus ensuring power quality. In addition, power electronics technology is developing rapidly, making re-use their power electronic converters as possible, using existing power electronic devices to absorb or release of active and reactive power, thereby improving the system of power quality, reduce the system's additional investment.

\section{The Impact on Relay of Distributed Power}

After the introduction of DG distribution network, distribution network to become more than one power supply system, the network will no longer be a pure single-supply, radial power supply network. If the size of the fault line occurs, short-circuit current, the flow of the action and reclosing DG behavior will be affected, making judgments based on existing protection system operation status quo cannot make the right judgments, may appear tripping, malfunction, coincidence gate unsuccessful, losing selective protection, reducing the sensitivity of protection and so on. If DG into existing distribution networks, the need for protection of existing methods and principles of setting a wide range of adjustments and modifications to this part of the study will be a new research direction.

Some scholars proposed system can be partitioned among the regions connected through the circuit breaker, the relay distribution station to complete the online induction failure, identify the fault type and fault area and issuing function trip signal to the corresponding circuit breaker by breaker District implements fault isolation and removal of fault zones DG systems, so as to ensure the normal operation of non-fault zone, and for transient fault reclosing implemented by the main relay. When there are a large number of methods for the DG access distribution network, a wide range of system loses its radial nature is very effective when, but the system still has a branch radically, and a region, as in the branch to the region any equivalent impedance power supply are likely the same, this method may not work.

\section{The Impact on Other of Distributed Power}

After the DG access to the distribution network, in addition to the distribution network will plan, net loss, trends, power quality, impact protection, but also have an impact on the stability of the distribution network. Furthermore, in order to achieve mutual coordination between DG systems and between systems and distribution networks and scheduling for distributed power, need to involve communications technology, GPS technology and online monitoring techniques applied research in distributed power generation and so on. China still needs to build distributed generation of electricity market system, the corresponding laws, regulations and industry standards. 


\section{Summary}

After the DG access to the distribution network, in addition to the distribution network will plan, net loss, trends, power quality, impact protection, but also have an impact on the stability of the distribution network. Furthermore, in order to achieve mutual coordination between DG DG systems and between systems and distribution networks and scheduling for distributed power, need to involve communications technology, GPS technology and online monitoring techniques applied research in distributed power generation and so on. China still needs to build distributed generation of electricity market system, the corresponding laws, regulations and industry standards

\section{References}

[1] El-Khattam W., Salama MMA Distributed generation technologies, definitions and benefits [J] .Electric Power Systems Research, 2004, 71 (2): 119-128.

[2] Püttgen Hans B., Macgregor Paul R., Lambert Frank C. Distributed generation: Semantic hype or the dawn of a new era [J] IEEE Power and Energy Magazine, 2003, 1 (1):. 22-29 .

[3] Daly Peter A., Morrison Jay, Understanding the potential benefits of distributed generation on power delivery systems [C]. Rural electric power conference, 2001, A21-A213.

[4] Zhao Yu, Yu Er keng. Electricity retail market research (vi) the impact of distributed generation power system [J] Automation of Electric Power Systems, 2003, 27 (15): 25-28.

[5] Fan Mingting international dynamic distribution system with distributed generation integrated research [J] Power and Electrical Engineers, 2008, 7 (4): 23-27.

[6] Chen Hai Yan. Of Power System Analysis with Distributed Generation [D]. Huazhong University of Science Doctoral Dissertation, 2008.

[7] Hu Chengzhi. Distributed Power Access System [D]. Chongqing University master's degree thesis, 2005. 